\title{
IMMEDIATE IMPLANT PLACEMENT IN MAXILLARY ESTHETIC ZONE WITHOUT AUGMENTING THE JUMPING GAP VERSUS THE USE OF AUTOGENOUS BONE PARTICULATES OR DEMINERALIZED BOVINE BONE GRAFT (RANDOMIZED CLINICAL TRIAL)
}

\author{
Mostafa Mahmoud Attiea*, Hesham Fattouh** and Mohamed Atef ${ }^{* * *}$
}

\begin{abstract}
Aim: to assess Immediate Implant Placement in Maxillary Esthetic Zone without Augmenting the Jumping Gap versus the Use of Autogenous Bone Particulates or Demineralized Bovine Bone Graft.

Material and Methods: This was a Randomized parallel controlled clinical trial conducted on 30 implant sites that indicated immediate implant placement in the maxillary esthetic zone divided into 3 groups equally: In group (A): immediate implants were inserted in the esthetic maxillary zone with no graft in the jumping gap. In group (B): immediate implants were inserted in the esthetic maxillary zone with demineralized bovine bone mineral (DBBM) in the jumping gap. In group (C): immediate implants were inserted in the esthetic maxillary zone with autogenous bone graft in the jumping gap. CBCT scans were performed immediately after the surgery and 6 months later for measuring horizontal bone changes at 3 levels (platform, mid implant, and apex level) of the labial plate of the bone and vertical bone changes labial and palatal plate of bone. Mean changes were compared between 3 groups using parametric statistics.
\end{abstract}

Results: The mean horizontal bone loss at platform level was $1.57 \pm 0.283 \mathrm{~mm}, 0.845 \pm 0.167$ $\mathrm{mm}$, and $1.226 \mathrm{~mm}$ at groups A (graft less group), B (xenograft group), and C (autogenous group) respectively. While at mean mid implant level was $1.155 \pm 0.3 \mathrm{~mm}, 0.754 \pm 0.185 \mathrm{~mm}$, and $0.829 \pm 0.31$ $\mathrm{mm}$ at group A (graft less group), B (xenograft group) \& C (autogenous group) respectively. Besides, the mean horizontal bone loss at the apex level of the implant was $0.195 \pm 0.061,0.326 \pm 0.103$ $\mathrm{mm}$, and $0.0182 \pm 0.026 \mathrm{~mm}$ at groups A (graft less group), B (xenograft group), \& C (autogenous group) respectively. On the other hand, the mean vertical bone loss at the labial plate of bone was $1.565 \pm 0.341 \mathrm{~mm}, 0.836 \pm 0.359 \mathrm{~mm}$, and $1.36 \pm 0.525 \mathrm{~mm}$ at group A (graft less group), B (xenograft group) \& $\mathrm{C}$ (autogenous group) respectively. While the mean vertical bone loss at the palatal plate of bone was $0.94 \pm 0.376 \mathrm{~mm}, 0.93 \pm 0.228 \mathrm{~mm}$, and $0.939 \pm 0.405 \mathrm{~mm}$ at group A (graft less group), $\mathrm{B}$ (xenograft group) \& C (autogenous group) respectively.

* Dental Specialist

** Associate Professor of Oral Surgery, Cairo University

*** Lecturer of Oral and Maxillofacial Surgery, Faculty of Dentistry, Cairo University 
Conclusion: the use of DBBM as a graft in the jumping gap showed the least bone dimensional changes in Comparison to no graft and autogenous bone graft group in immediate implant placement.

KEYWORDS: Immediate implant, demineralized bovine bone mineral, Graft, autogenous bone graft, jumping gap Esthetic zone.

\section{INTRODUCTION}

Nowadays, non-restorable anterior maxillary teeth have become an emergency for patients. The traditional way for treating such a case is to extract the tooth and wait until 3-6 months for complete healing of bone and soft tissue. However, the investigators found that the amount of bone resorption after tooth extraction was 2.4-4.6 mm horizontally and 0.4-3.9 mm vertically ${ }^{(1)}$ and Most of these changes happened in the first year mainly in the first 3 months. ${ }^{(2)}$

There are 2 main reasons after the bone resorption after exodontia: tooth extraction, the periodontal ligament diminished and lamellar bone surrounding the tooth resorbed rapidly as a response to the alteration of blood supply affect the mainly horizontal and vertical level of labial bone and the thickness of labial bone which is in mostly less than $1 \mathrm{~mm}$ in thickness. ${ }^{(3)}$

Besides the bony changes, the soft tissue level as $50 \%$ of soft tissue changes happened in the first 2 weeks. Besides the thin biotype gingiva increased in thickness by 7 folds converted to thick biotype which may cause mislead the clinicians during implant placement. ${ }^{(4)}$

In 1976, prof. Schulte presents an immediate implant placement as a treatment option with his Tuebingen implant which provides a lot of benefits for both patients and clinicians. The immediate implant placement decreases the time of treatment, number of surgeries, surgical morbidity, and amount of bone resorption after tooth extraction. ${ }^{(5)}$

The immediate implant principle was supposed to prevent bone resorption but the studies showed the bone resorption occurred but only kept in its average range. Due to that, the main drawback of immediate implant placement was the mid-gingival recession ${ }^{(6)}$. in a systematic review, Khzam et al found that the mid gingival recession most likely to happen in most cases ranged from $0.23 \mathrm{~mm}-0.27$ $\mathrm{mm}$ while advanced recession $(>1 \mathrm{~mm})$ also found but only in $11 \%$ of cases. ${ }^{(7)}$

Ideally, the position of the implant was bodily palatal in the socket with at least a 2 mm gap between the implant and labial bone. This position provides adequate blood clot thickness labially to support bone during the modeling and remodeling process. Augmentation of the jumping gap between labial bone and implant plays an important role in the esthetic success of the dental implant. Tarnow et al suggested that no graft is needed when the jumping gap exceeded $2 \mathrm{~mm}$. besides, autogenous bone particulates, allograft, and xenograft bone particles were used as augmentation surrounding immediate implant as the graft act as a scaffold for a blood clot in the initial healing, support hard and soft tissue volume and minimize dimensional bone changes ${ }^{(3)}$. The researchers suggest that augmentation of the jumping gap between the implant and labial bone could help in supporting blood clots and decrease bone resorption which helps in better esthetics. Autogenous bone is considered the gold stander in augmentation procedures because of its ability to osteogenesis, osteoinduction, and osteoconduction. Also, the demineralized bovine bone mineral was augmented in the jumping gap because of its ability to osteoconductive with a low resorption rate which allows enough time for the bone formation. As well as the small particles of xenograft were also used to allowing proper condensation easily and well adapted in narrow spaces around the implant. ${ }^{(8)}$ 
Studying the effect of augmentation of the jumping gap between the implant and buccal with xenograft in a randomized clinical trial, twenty patients were treated with twenty-seven immediately placed implants divided into 2 groups with and without xenograft in the jumping gap. CBCT was performed before, immediately after the surgery, and 4-6 months after extraction. The results showed a significant bone reduction in both groups between baseline CBCT and follow-up ones regarding bone height. Also, no significant difference in bone resorption vertically as the measurements were $1.3 \mathrm{~mm}$ in augmented implants and $1.66 \mathrm{~mm}$ in non-augmented implants. The study showed that xenograft with an immediate implant failed to prevent bone resorption. ${ }^{(9)}$

Others evaluated the long-term follow-up on the soft and hard tissue changes for 5 years' follow-up after immediate implant placement and provisionalization using an autogenous bone graft. 21 patients were received 37 implants in the maxillary esthetic zone by flapless approach despite the presence of a labial bone defect or not. The results showed that a significant reduction in facial bone lamellae between preoperative and 1-year follow-up measurements. However, no significant changes in the following 4 years of measurement. Besides, that, all implants provide satisfactory esthetic as the mean pink esthetic score was 10.7 and remain constant for the 5 years' follow-up. The author concluded that the majority of changes occur in the first year after implant placement and the results remained stable during 5 years follow up. ${ }^{(10)}$

\section{PATIENTS AND METHODS}

\section{Study Design}

The present study was a randomized clinical trial, parallel design with an allocation ratio of 1:1:1. The study was approved by the ethics committee at the faculty of Dentistry Cairo University and Candidates with non-restorable maxillary anterior tooth or teeth and seeking restoration with implant placement were selected from the outpatient clinic of Implantology, Faculty of Dentistry, Cairo University.

\section{Inclusion Criteria:}

1. Patient of both sexes with non-restorable maxillary anterior teeth

2. Any periodontal phenotype (thin, normal, or thick).

3. An intact labial plate of bone with Thickness $\geq 0.5 \mathrm{~mm}$ on the CBCT scan (type 1 Elian classification).

4. Preapical bone $\geq 3 \mathrm{~mm}$ on the CBCT scan for high primary stability.

\section{Exclusion Criteria}

1. Patients with systemic disease that may affect normal bone remodeling

2. Smoker patients

3. History of radiation therapy to the head and neck

3. Patients with parafunctional habits such as bruxism or clenching 5- Teeth with present periodontal disease

The ethics committee of the Faculty of Dentistry, Cairo University, approved the present study.

\section{Randomization}

Thirty extraction sockets were randomly divided into three groups using block randomization with stratification (block size 4) using a formula on Microsoft excel software into (table 1)

\section{Group A (No graft group):}

Included 10 extraction sockets in patients who received an immediate post-extraction implant placement with no graft to the jumping gap between the residual labial bone and implant surface with immediate temporization. 
Table (1): Patients Demographic Data

\begin{tabular}{|c|c|c|c|c|}
\hline $\begin{array}{c}\text { Implant } \\
\text { no }\end{array}$ & Patient & Site & age & Sex \\
\hline 1.2 & A & UR1,UL1 & 28 & $\mathrm{~F}$ \\
\hline $3,4,5,6$ & B & UR2,UR1,UL1,UL2 & 37 & $\mathrm{~F}$ \\
\hline 7,8 & $\mathrm{C}$ & UL2,UL4 & 34 & M \\
\hline 9 & $\mathrm{D}$ & UL2 & 35 & M \\
\hline 10 & $\mathrm{E}$ & UL3 & 27 & $\mathrm{~F}$ \\
\hline 11,12 & $\mathrm{~F}$ & UR2,UL1 & 30 & $\mathrm{~F}$ \\
\hline $13,14,15$ & G & UR1,UL2,UL4 & 33 & M \\
\hline 16 & $\mathrm{H}$ & UL1 & 34 & M \\
\hline 17,18 & I & UR1,UL1 & 33 & $\mathrm{~F}$ \\
\hline 19 & $\mathrm{~J}$ & UL2 & 40 & M \\
\hline 20 & K & UR1 & 45 & M \\
\hline 21 & $\mathrm{~L}$ & UR2 & 25 & $\mathrm{~F}$ \\
\hline $22,23,24$ & M & UR3,UR1,UL2 & 35 & $\mathrm{~F}$ \\
\hline 25 & $\mathrm{~N}$ & UR3 & 38 & M \\
\hline 26 & $\mathrm{O}$ & UL3 & 27 & M \\
\hline 27 & $\mathrm{P}$ & UL2 & 36 & $\mathrm{~F}$ \\
\hline 28,29 & $\mathrm{R}$ & UR4,UL2 & 41 & $\mathrm{~F}$ \\
\hline 30 & Q & UR1 & 45 & M \\
\hline
\end{tabular}

\section{Group B (Xenograft graft group)}

Included 10 extraction sockets in patients which received an immediate post-extraction implant placement with xenograft to augment the gap between the residual labial bone and implant surface with immediate temporization.

\section{Group C (Autogenous graft group)}

Included 10 extraction sockets in patients which received immediate post-extraction implant placement with autogenous bone particulates to augment the gap between the residual labial bone and implant surface with immediate temporization.'

\section{Pre-operative Preparation}

Patients were inspected for adequate Inter- arch and mesiodistal space. A thorough periodontal examination was carried out checking the mucosa color, contour, and consistency. Probing depth readings was recorded and checked for any bleeding on probing. The primary impression to the upper arch has been taken for study cast followed by prefabrication of acrylic temporary crown.

A preoperative digital panoramic radiograph (figure1) (OPG) with 1:1 magnification was taken for each patient as a primary survey to the area of interest. A Cone Beam Computed Tomography CBCT scan was ordered for the enrolled candidates to assess the labial bone thickness, available bone height and select the proper implant size to be used. A scout view was obtained and adjustments were made to ensure that all patients were correctly aligned in the scanner according to the adjustment of the light beam before the acquisition. The machine was supplied with Amorphous Silicon Flat Panel Sensor with Cesium Iodide (CsI) scintillator, 0.5 $\mathrm{mm}$ focal spot size, and 14-Bit greyscale resolution

T6 implants (Nucleoss Company - turkey) with diameters $3.5 \mathrm{~mm}$ and length $14 \mathrm{~mm}$. It has a cylindrical body design with double threads with reverse buttress allowing easier installation. The implant was characteristic of acid-etched and sandblasted surface treatment that facilitates

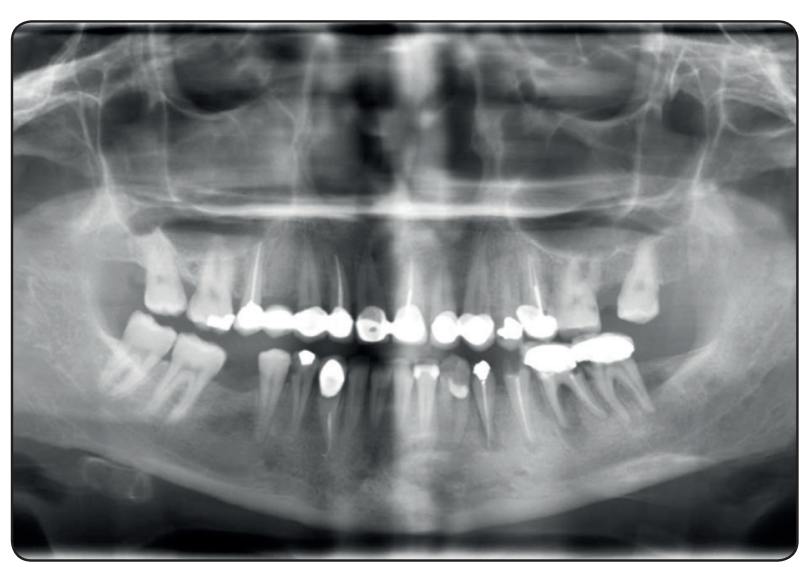

Fig. (1): Preoperative Panoramic View 
the osseointegration process. All implant sizes share the same internal hex.

Treatment before surgery included plaque control and oral hygiene measures instructions. After extraoral disinfection of the surgical site. Patients were asked to rinse their mouths with Chlorohexidine HCL $1.25 \%$ mouthwash immediately preoperatively.

\section{Surgical method}

All procedures were performed under local infiltration anesthesia [Articaine 4\% 1:100000 epinephrine] was used. Atraumatic flapless extraction was done using periotomes and Micro- elevators with gentle pressure toward mesial and distal with caution to avoid any pressure to the labial plate of bone with finger support to the labial and palatal plate of bone. Then removing of the root by upper anterior forceps. (figure2)

Meticulous mechanical debridement of the extraction socket was carried out using a bone curette to remove any soft tissue remnants or granulation tissue. All debris was washed out using copious saline irrigation. Drilling by piolet drill with angulation 45 degrees on palatal bone and as the drill going deeper in the palatal bone straightening up the drill for full length until forming implant bed bodily palatal. Using the subsequent drill with the previous technique with checking the proper angulation mesiodistally, Bucco-palatally, and corono apically.

As the implant mesiodistally should be in the middle of the socket with $1.5 \mathrm{~mm}$ away from neighboring teeth or $3 \mathrm{~mm}$ away from neighboring implants, Bucco-palatally the implant should be away $2 \mathrm{~mm}$ or more from the inner surface of labial bone taking into consideration that the implant should be located bodily palatal and Crono-apically should be $3-4 \mathrm{~mm}$ below the labial free gingival margin. (figure3)

Implant insertion has been installed using with minimal torque $35 \mathrm{n} / \mathrm{cm}$ torque or more with

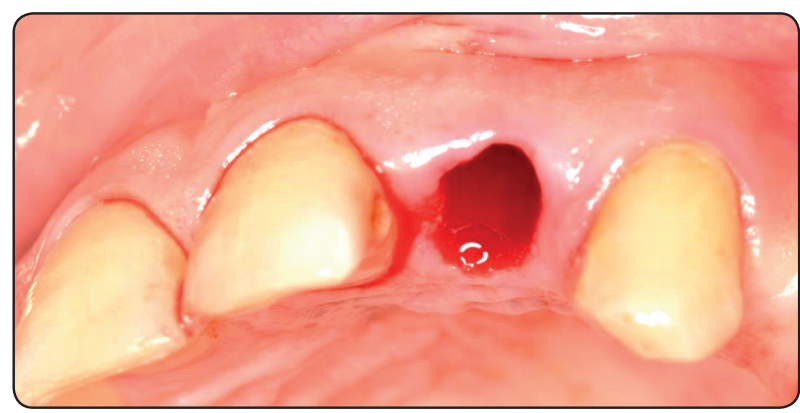

Fig. (2): Atraumatic Extraction

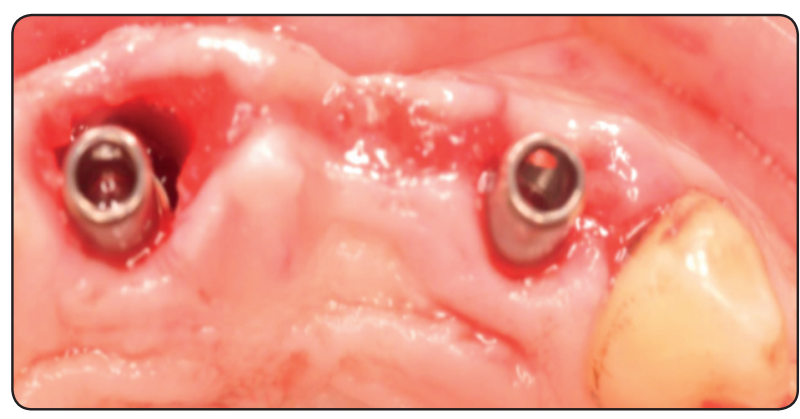

Fig. (3): Implant placed palatally leaving a jumping gap of approximately $2 \mathrm{~mm}$

rechecking of the position of the implant after insertion. After insertion of the Stock abutment on the implant, the prefabricated provisional crown was adjusted to the abutment. Creating the emergence profile taking into consideration being flat or slightly concave using flowable composite.

Removing abutment and checking the emergence profile to obtaining concave shape interproximal to maintain papilla and labially to support labial gingiva. Finishing of composite with finishing burs and stones and polishing with wheel for achieving smooth surface to encourage gingival formation and growth and to avoid bacterial and food debris accumulation. Reinsertion of abutment with temporary crown any observation of any blenching on gingiva lasting more than 10 minutes to avoid pressure necrosis of gingiva.

Recall patients after 48 hours for rechecking occlusion and making immediate post-operative CBCT. Patient instruction with oral hygiene measurements after 1 week and 1 month for follow- 
up and after 3 months for final prosthesis fabrication follow up after 6 months.

In all patients, a cone-beam computed tomography (CBCT) was made immediately after surgical procedure and 6 months later to assess the horizontal and vertical dimensional changes to the labial plate of bone. Sagittal images were used to measure bone dimensional changes.

For horizontal bone level, on axial view drawing a panoramic curve on the center of the teeth at the implant from panoramic view we select crosssection passing through the midline of the implant. the line is drawn passing through the center of the implant $(3.7 \mathrm{~mm} / 2)$ and divided this line into two equal divisions connected with three points $(\mathrm{m}, \mathrm{m} 2$, $\mathrm{m} 3$ ). $\mathrm{m} 1$ indicated to cervical point at the platform of the implant., $\mathrm{m} 2$ indicated to point at half of the implant length $(7 \mathrm{~mm})$ and $\mathrm{m} 3$ indicated to point at the apical part of the implant (14 mm). Another line is drawn from the labial margin of the labial plate of bone perpendicular to the centerline of the implant at $(\mathrm{m}, \mathrm{m} 2$, and $\mathrm{m} 3)$ to record the distance between the centerline of the implant to the labial margin of the labial plate at three points (m, m2, m3). The average difference between the horizontal distances at 3 levels immediately after surgery and after 6 months represented the horizontal bone changes at different levels, shown in figure (4A, 4B).

For vertical bone level, on axial view drawing a panoramic curve on the center of the teeth at the implant. From a panoramic view, we select a cross-section passing through the midline of the implant. Then, the line was drawn passing through the center of the implant $(3.7 \mathrm{~mm} / 2)$. Another line was drawn passing through the implant platform perpendicular to the centerline of the implant $(\mathrm{T}$ line). From the labial crest of the bone, a line was drawn perpendicular to the ( $\mathrm{T}$ line). The distance between the labial bone crest and the ( $\mathrm{T}$ line) were recorded immediately after surgery and 6 months post-operative and from the palatal crest of bone at implant, a line was drawn perpendicular to the ( $\mathrm{T}$ line) The distance between the palatal bone crest and the (T line) was recorded immediately after surgery and 6 months post-operative. The average difference between the vertical distances immediately after surgery and after 6 months represented the vertical bone loss at different levels, shown in figure (4C, 4D).

The Pink Esthetic Score (PES) was based on seven variables: mesial papilla, distal papilla, softtissue level, soft tissue contour, alveolar process deficiency, soft-tissue color, and texture (figure 34). Each variable was assessed with a 2-1-0 score, with 2 being the best and 0 being the poorest score. The mesial and distal papilla were evaluated for completeness, incompleteness, or absence. All other variables were assessed by comparison with a reference tooth, i.e. the corresponding tooth (anterior region) or a neighboring tooth (premolar region). The highest possible score reflecting a perfect match of the peri-implant soft tissue with that of the reference tooth was 14 , shown in figure (5).

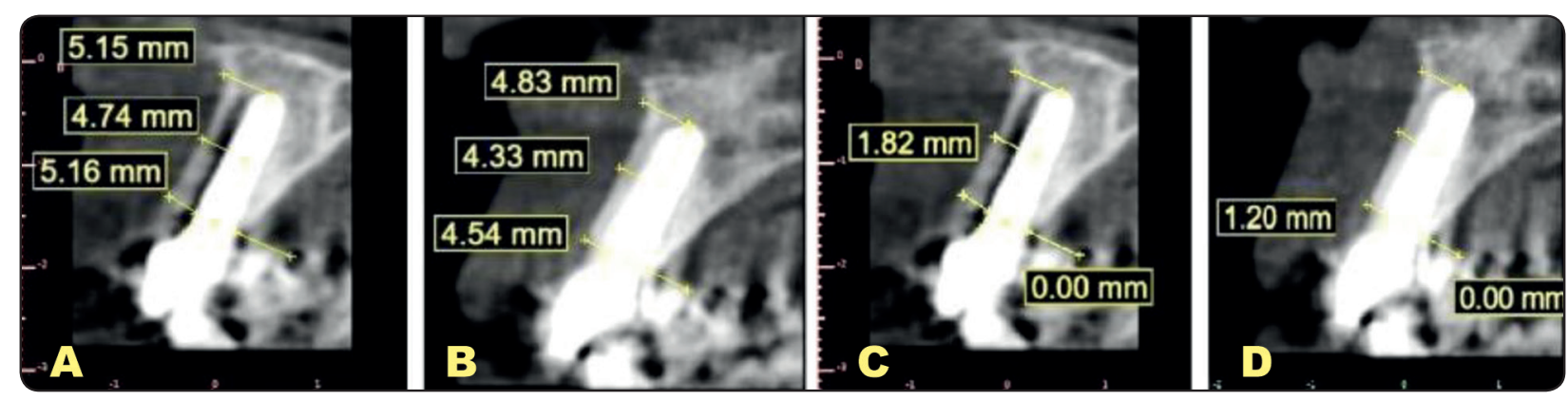

Fig. (4): (A) Horizontal Bone Level Immediately Postoperative. (B) Horizontal Bone Level after Six Months. (C) Vertical Bone Level Immediately Postoperative. (D) Vertical Bone Level after Six Months. 


\section{Statistical Analysis}

Data management and statistical analysis were performed using the Statistical Package for Social Sciences (SPSS) version 22. Numerical data were summarized using means and standard deviations. Data were explored for normality using the Kolmogorov-Smirnov test and the Shapiro- Wilk test. Comparisons between 3 groups and overtime were done by 2 way repeated measures ANOVA. Comparisons between the 2 groups at each time point were done using the independent t-test. Overtime comparisons in each group were done by repeated measure ANOVA followed by a Post hoc paired t-test. All p-values are two-sided. P-values $\leq$ 0.05 were considered significant.

\section{RESULTS}

Assessment of facial vertical bone loss of group, (A) (Graft-less), group (B) (Xeno-Graft) and group (C) (Autogenous-Particulate), mean \pm standard deviation was $(1.565 \pm 0.341),(0.836 \pm$ $0.359)$ and (1.36 \pm 0.525$)$ respectively, all listed in the table (2) and showed in figure (6). Using oneway analysis of variance test followed by Tukey`s post hoc test for multiple comparisons, there was a significant difference between all groups, as the value of probability level lower than 0.05 , listed in the table (2). While for palatal vertical bone loss, group, (A) (Graft-less), group (B) (Xeno-Graft), and group (C) (Autogenous-Particulate), mean \pm standard deviation was $(0.94 \pm 0.376),(0.93 \pm$ $0.228)$, and $(0.939 \pm 0.405)$ respectively, all listed in the table (2) and showed in figure (4). Using oneway analysis of variance test followed by Tukey`s post hoc test for multiple comparisons, there was insignificant difference between all groups, as the value of probability level higher than 0.05 , listed in the table (2).

Assessment of platform level of horizontal bone loss of group, (A) (Graft-less), group (B) (Xeno-
Graft) and group (C) (Autogenous-Particulate), mean \pm standard deviation was $(1.57 \pm 0.283),(0.845$ $\pm 0.167)$ and $(1.226 \pm 0.248)$ respectively, all listed in the table (3) and showed in figure (6). Using oneway analysis of variance test followed by Tukey's post hoc test for multiple comparisons, there was a significant difference between all groups, as the value of probability level lower than 0.05 , listed in the table (3). While mid-level of horizontal bone loss of group, (A) (Graft-less), group (B) (Xeno-Graft) and group (C) (Autogenous-Particulate), mean \pm standard deviation was $(1.155 \pm 0.3),(0.754 \pm 0.185)$ and $(0.829 \pm 0.31)$ respectively, all listed in the table (3) and showed in figure (6). Using - way analysis of variance test followed by Tukey's post hoc test for multiple comparisons, there was a significant difference between all groups, as the value of probability level lower than 0.05 , listed in the table (3). Regarding apex level of horizontal bone loss of group, (A) (Graft-less), group (B) (Xeno-Graft) and group (C) (Autogenous-Particulate), mean \pm standard deviation was $(0.195 \pm 0.161),(0.326 \pm$ $0.13)$, and $(0.182 \pm 0.14)$ respectively, all listed in the table (3) and showed in figure (6). Using oneway analysis of variance test followed by Tukey`s post hoc test for multiple comparisons, there was insignificant difference between all groups, as the value of probability level higher than 0.05 , listed in the table (3).

After six months of follow up evaluation of the pink esthetic score of the group, (A) (Graft-less), group (B) (Xeno-Graft), and group (C) (AutogenousParticulate), mean \pm standard deviation was $(11 \pm$ $1.49),(11.8 \pm 1.13)$ and $(12.5 \pm 0.527)$ respectively, all listed in the table (3) and showed in figure (7). Using one-way analysis of variance test followed by Tukey`s post hoc test for multiple comparisons, there was a significant difference between all groups, as the value of probability level lower than 0.05 , listed in the table (4). 
TABLE (2): Comparison of Facial and Palatal Vertical Bone Loss between Group (A), (B) and (C) during Six Months Follow Up.

\begin{tabular}{|l|c|c|c|c|}
\hline \multirow{2}{*}{} & \multicolumn{3}{|c|}{$\mathrm{M} \pm \mathrm{SD}$} & \multirow{2}{*}{ P-value } \\
\cline { 2 - 5 } & $\begin{array}{c}\text { Group (A) } \\
\text { (Graft-less) }\end{array}$ & $\begin{array}{c}\text { Group (B) } \\
\text { (Xeno-graft) }\end{array}$ & $\begin{array}{c}\text { Group (C) } \\
\text { (Autogenous-Particulate) }\end{array}$ & \\
\hline Facial Vertical Bone Loss & $1.565 \pm 0.341 \mathrm{a}$ & $0.836 \pm 0359 \mathrm{~b}$ & $1.36 \pm 0.525 \mathrm{a}$ & $0.0017 *$ \\
\hline Palatal Vertical Bone Loss & $0.94 \pm 0.376 \mathrm{a}$ & $0.93 \pm 0.228 \mathrm{a}$ & $0.939 \pm 0.405 \mathrm{a}$ & 0.9975 \\
\hline
\end{tabular}

M: Mean, SD: Standard Deviation, P: Probability level, Means with the same superscript letter in the same row were insignificant different, Means with the different superscript letter in the same row were significant different, *significant difference

TABLE (3): Comparison of Facial and Palatal Vertical Bone Loss between Group (A), (B) and (C) during Six Months Follow Up.

\begin{tabular}{|c|c|c|c|c|}
\hline \multirow{2}{*}{} & \multicolumn{3}{|c|}{ M \pm SD } & \multirow{2}{*}{ P-value } \\
\cline { 2 - 5 } & $\begin{array}{c}\text { Group (A) } \\
\text { (Graft-less) }\end{array}$ & $\begin{array}{c}\text { Group (B) } \\
\text { (Xeno-Graft) }\end{array}$ & $\begin{array}{c}\text { Group (C) } \\
\text { (Autogenous-Particulate) }\end{array}$ & \multirow{2}{*}{$<0.0001^{*}$} \\
\hline $\begin{array}{c}\text { Horizontal Bone Loss at Plat- } \\
\text { form Implant Level }\end{array}$ & $1.57 \pm 0.283^{\mathrm{a}}$ & $0.845 \pm 0.167^{\mathrm{b}}$ & $0.226 \pm 0.248^{\mathrm{c}}$ & $0.0061^{*}$ \\
\hline $\begin{array}{c}\text { Horizontal Bone Loss at Mid- } \\
\text { Level Implant }\end{array}$ & $1.155 \pm 0.3^{\mathrm{a}}$ & $0.754 \pm 0.185^{\mathrm{b}}$ & $0.182 \pm 0.14^{\mathrm{a}}$ & 0.064 \\
\hline $\begin{array}{c}\text { Horizontal Bone Loss at Im- } \\
\text { plant Apex Level }\end{array}$ & $0.195 \pm 0.161^{\mathrm{a}}$ & $0.326 \pm 0.13^{\mathrm{a}}$ & 0.29 & \multirow{2}{*}{} \\
\hline
\end{tabular}

M: Mean, SD: Standard Deviation, P: Probability level, Means with the same superscript letter in the same row were insignificant different, Means with the different superscript letter in the same row were significant different, *significant difference

Table (4): Comparison of pink esthetic score between 3 groups after 6 months:

\begin{tabular}{|l|c|c|c|c|}
\hline \multirow{2}{*}{} & \multicolumn{3}{|c|}{ M \pm SD } & \multirow{2}{*}{ P-value } \\
\cline { 2 - 5 } & $\begin{array}{c}\text { Group (A) } \\
\text { (Graft-less) }\end{array}$ & $\begin{array}{c}\text { Group (B) } \\
\text { (Xeno-graft) }\end{array}$ & $\begin{array}{c}\text { Group (C) } \\
\text { (Autogenous-Particulate) }\end{array}$ & \\
\hline Pink Esthetic Score & $11 \pm 1.49^{\mathrm{a}}$ & $11.8 \pm 1.13^{\mathrm{b}}$ & $12.5 \pm 0.527^{\text {a }}$ & $0.0209^{*}$ \\
\hline
\end{tabular}

M: Mean, SD: Standard Deviation, P: Probability level, Means with the same superscript letter in the same row were insignificant different, Means with the different superscript letter in the same row were significant different, *significant difference 


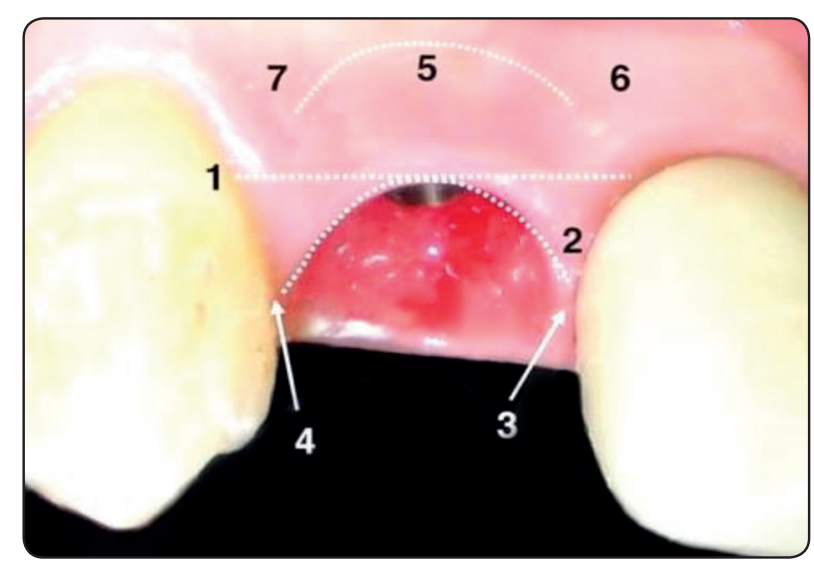

Fig. (5): Pink Esthetics Evaluation

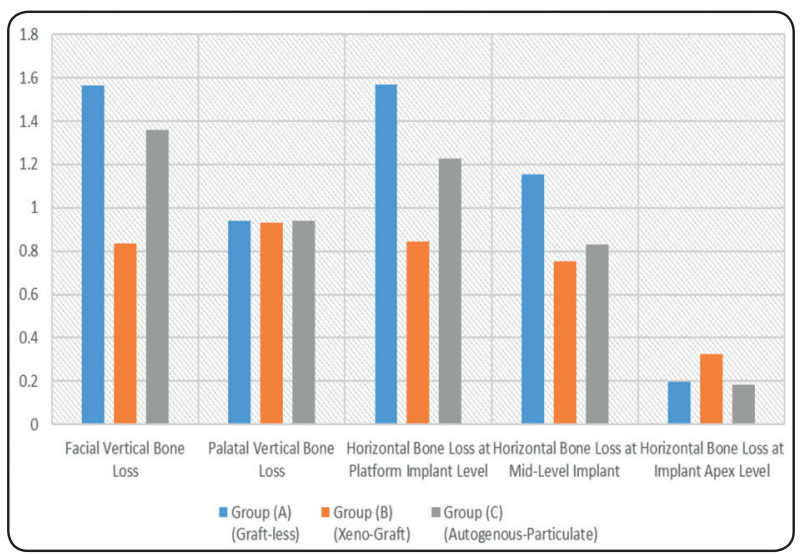

Fig. (6): Bar Chart of Horizontal and Vertical Bone Loss between Group (A), (B) and (C) after Six Months Follow Up

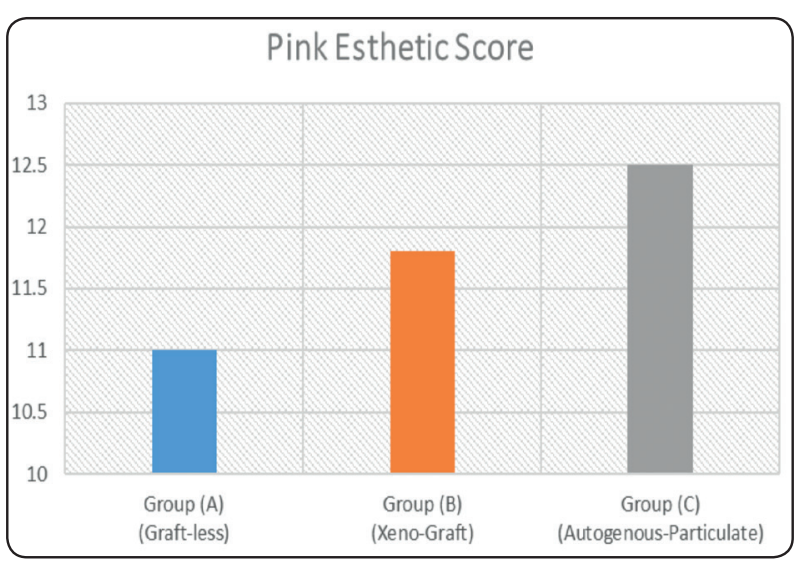

Fig. (7): Bar Chart of Pink Esthetic Score between Group (A), (B) and (C) after Six Months Follow Up

\section{DISCUSSION}

Autogenous bone is considered the gold stander in augmentation procedures because of its ability to osteogenesis, osteoinduction, and osteoconduction. In group $\mathrm{C}$ of the present study (autogenous bone group), the autogenous bone particulates were harvested from the socket by using drills with lowspeed mode. Also harvesting a cortico-cancellous bone from the external oblique ridge was used by ACM bur when the larger amount was needed. The advantage of ACM bur was to keep well viability of bone and decrease the possibility of soft tissue injury during harvesting. However, another surgery causing a discomfort feeling to the patient with more morbidity and postoperative pain. While in group B (xenograft group) small bone particulates $(0.25 \mathrm{~mm}-1 \mathrm{~mm})$ xenograft was used to be condensed in the jumping gap because of its ability to osteoconductive with low resorption rate which allows enough time form formation of bone. As well as the small particles of xenograft were also used to allowing proper condensation easily and well adapted in narrow spaces around the implant.

A CBCT scan was used for evaluating the effect of different grafting materials (autogenous bone particulates or xenograft) on the reduction of horizontal and vertical bone resorption. The results showed that mean horizontal bone resorption at the platform level of the implant was $1.57 \mathrm{~mm}, .875 \mathrm{~mm}$, and $1.226 \mathrm{~mm}$ in groups $\mathrm{A}, \mathrm{B}$, and $\mathrm{C}$ respectively. It was reported that the mean horizontal bone loss at the platform level of the implant with autogenous bone particulates was $1.19 \mathrm{~mm}$. which is similar to group $\mathrm{C}$ results of the present study (autogenous bone group) with $1.226 \mathrm{~mm}$ bone reduction in platform level of the implant. However, it was noticed a decrease in the amount of bone resorption along the following 5 years' follow-up results showed mean bone loss horizontally at the platform of implant $1.18 \mathrm{~mm} .^{(10)}$ 
In the present study vertical bone loss at the labial plate in group B (xenograft graft group) was $0.836 \mathrm{~mm}$ and in group A (no graft group) was $1.565 \mathrm{~mm}$ while showing mean vertical bone loss using xenograft at the labial plate was $1.3 \mathrm{~mm}$ and $1.66 \mathrm{~mm}$ in the xenograft group and no graft group respectively. The difference between the results may come from suturing the socket in the author's study. Suturing the socket may apply additive pressure on the thin labial plate of bone beside disturbance in blood supply after extraction which may increase resorption in the short and long term without giving any data about horizontal bone resorption, on the other hand, using a temporary crown or customized healing collar as socket seal instead suturing may give a decrease in vertical and horizontal bone loss. Also suturing the socket may cause rapid healing of soft tissue before the complete organization of blood clots resulting in soft tissue invasion inside the socket, which increases bone resorption horizontally and vertically. ${ }^{(9)}$

Systematic review and meta-analysis presented the amount of bone resorption between different techniques of immediate implant augmentation and flap or flapless. His results showed that flapless with provisionalization and augmenting gap with deproteinized bovine bone lead to mean bone loss horizontally $1.02 \mathrm{~mm}$ regardless of the type of bone augmentation while in the present study the mean horizontal bone loss at platform level was 0.875 and 1.225 at group B (xenograft group) and group C (autogenous group) respectively. ${ }^{(11)}$

Researchers augment the jumping gap with allograft and restorable membrane. The mean bone changes between immediate measurements and postoperative CBCT were $0.69 \mathrm{~mm}$ at the platform level, $0.41 \mathrm{~mm}$ at mid implant level, and $0.004 \mathrm{~mm}$ at apex level which slightly lower than the results of the present study epically grafted groups (group B and C) as there mean a horizontal bone loss at crest were $0.845 \mathrm{~mm}$ and $1.2 \mathrm{~mm}$ respectively, and at mid implant were $0.754 \mathrm{~mm}$ and $0.829 \mathrm{~mm}$ respectively and at implant apex were 0.326 and $0.082 \mathrm{~mm}$ respectively. this difference in results may be because of the author's usage of prefabricated polymethyl methacrylate shell (i shell) which helps in maintaining soft tissue architect and prevents soft tissue collapse after tooth extraction and before the formation of the provisional crown. ${ }^{(12)}$

In the present study, the provisional crown was fabricated chairside with concaves- shape or flat emergence profile according to the position of the implant, however, the concave design is more preferable because of the increased thickness of labial soft tissue which assists in the preservation and to maintain the tissue more stable over time. the soft tissue will appear very healthy with a clear pink color. ${ }^{(3)}$ No mid gingival recession was noticed in the present study as provisionalization minimizes mid gingival recession which is the main drawback of immediate implant and the effect of immediate provisionalization with immediate implant placement on facial recession with which showed more tissue stability. ${ }^{(13)}$ It was recommended immediate temporization with immediate implant placement as the use of anatomically contoured provisional restorations may provide a platform to promote peri-implant soft tissue healing and minimize remodeling of the labiopalatal ridge dimension. ${ }^{(14)}$

\section{CONCLUSION}

Immediate implant placement with provisionalization with augmenting jumping gap provides a successful treatment option for non-restorable teeth in the anterior maxillary esthetic zone. The use of demineralized bovine bone as a graft showed the least dimensional bone change without surgical morbidity harvesting autogenous bone graft. Provisionalization of the immediate implant maintains the natural emergence profile besides supporting soft tissue and minimize soft tissue dimensional changes. 


\section{REFERENCE}

1. Ten Heggeler JM, Slot DE, Van der Weijden GA.; Effect of socket preservation therapies Following tooth extraction in non-molar regions in humans: a systematic review. Clinical Oral Implants Res: 2011, 22: 779-788.

2. Schropp, L. \& Wenzel, A. \& Kostopoulos, L. \& Karring, T.; Bone healing and soft tissue contour changes following single-tooth extraction: A clinical and radiographic 12month prospective study. The International journal of periodontics \& restorative dentistry: 2003, 23.313-23

3. Tarnow, D. P. (n.d.).; Single-Tooth Implant, A Minimally Invasive Approach for Anterior and Posterior Extraction Sockets. Quintessence Publishing.

4. Chappuis V., Engel O., Shahim K., Reyes M., Katsaros C., Buser D.; Soft tissue alterations in esthetic postextraction sites: a3-dimensional analysis. J Dent Res: 2015, 94: 187193.

5. Schulte W, Heimke G. The Tübinger; Immediate implant. Quintessenz 1976; 27(6): 17-23.

6. Buser, D., Chappuis, V., Belser, U. C., \& Chen, S.; Implant placement post extraction in esthetic single tooth sites: when immediate, when early, when late? Periodontology 2017, 73(1), 84-102.

7. Khzam N., Arora H., Kim P., Fisher A., \& Mattheos N.; Systematic Review of Soft Tissue Alterations and Esthetic Outcomes Following Immediate Implant Placement and Restoration of Single Implants in the Anterior Maxilla.: 2015, 1-15. 10.1902

8. Albrektsson T, Johansson C.; Osteoinduction, osteoconduction and osseointegration. Eur Spine J. 2001 Oct; 10 Suppl 2(Suppl 2): S96-101. doi: 10.1007/s005860100282. PMID: 11716023; PMCID: PMC3611551.

9. Paknejad M., Akbari S., Aslroosta H., Panjnoush M., Hajheidary S.; Effect of Flapless Immediate Implantation and Filling the Buccal Gap with Xenograft Material on the Buccal Bone Level: A Randomized Clinical Trial. J Dent.; 14(6): 2017, 344-351.

10. Noelken, R., Moergel, M., Kunkel, M., \& Wagner, W.; Immediate and flapless implant insertion and provisionalization using autogenous bone grafts in the esthetic zone: 5-year results. Clinical Oral Implants Research: 2018, 29(3), 320-327.

11. De Risi V, Clementini M, Vittorini G, Mannocci A, De Sanctis M.; Alveolar ridge preservation techniques: a systematic review and meta-analysis of histological and histomorphometric data. Clin Oral Implants Res. 2015 Jan;26(1):50-68. DOI: 10.1111/clr.12288. Epub 2013 Nov 1. PMID: 27007188.

12. Sarnachiaro G., Chu S., Sarnachiaro E, Gotta S., Tarnow D.; Immediate Implant Placement into Extraction Sockets with Labial Plate Dehiscence Defect. Clin Implant Dent Related Res., 2016, 18(4):821-9.

13. De Rouck T, Collys $\mathrm{K}$ and Cosyn J; Immediate singletooth implants in the anterior maxilla: a 1-year case cohort study on hard and soft tissue response. Journal of Clinical Periodontology: 2009, 35:649-657.

14. Redemagni M, Garlini G and Amato S.; Key Factors for Predictable Aesthetics in Single Tooth Immediate Implantation with provisionlization. Oral Health and Dental Mangement: 2013, 12:222-229. 